\title{
Efeito de diferentes doses de esterco de aves no crescimento e florescimento de 'Lulo' (Solanum quitoense var. septentrionale)
}

\section{Effect of different doses of poultry manure on growth and flowering of 'Lulo' (Solanum quitoense var. septentrionale)}

\author{
Uirá do Amaral ${ }^{1}$, Gustavo de Paulo Souza ${ }^{2}$, Isabella Borges Silva ${ }^{3}$, Maurício José Lemos Junior ${ }^{4}$, Valdineia Maria dos \\ Santos $^{5}$
}

Resumo: O cultivo de frutas exóticas ocupa um espaço importante dentro da fruticultura, dentre as muitas espécies com potencial de exploração, a cultura do lulo se destaca por apresentar excelentes características nutricionais, tais como, propriedades antioxidantes, presença de vitamina A e C, proteínas, pepsina e minerais. $\mathrm{O}$ objetivo deste trabalho foi avaliar o efeito de doses crescentes de esterco de aves na cultura do lulo em sistema orgânico de produção. O experimento foi instalado na área experimental da Faculdade de Filosofia e Ciências Humanas - FAFICH no munícipio de Goiatuba-GO, no período de novembro de 2014 a março de 2015. O delineamento experimental empregado foi o de blocos casualizados com quatro tratamentos e cinco repetições. Os tratamentos foram: 0,0;0,72; 2,17 e 6,52 $\mathrm{kg}_{\text {planta }}{ }^{-1}$ de esterco de aves curtido, sendo que cada tratamento foi fracionado em três doses iguais. As plantas foram avaliadas durante as fases de crescimento, sendo as variáveis: altura de plantas $(\mathrm{cm})$; diâmetro do caule $(\mathrm{cm})$; comprimento e largura da $3^{\mathrm{a}}$ folha $(\mathrm{cm})$; início do florescimento (antese) e teor de clorofila (Índice SPAD). Observou-se que aos 180 dias após o transplantio (DAT) o aumento das doses de esterco de aves proporcionou um crescimento significativo nas plantas, obtendo os melhores resultados na dosagem de (6,09 $\mathrm{kg}_{\text {planta }}{ }^{-1}$ ) onde a variável altura de plantas atingiu $32,35 \mathrm{~cm}$.

Palavras-chaves: Adubação nitrogenada. Desempenho produtivo. Agricultura orgânica. Pequenas frutas.

\begin{abstract}
The exotic fruit cultivation occupies an important place within the horticulture, among the many species with potential for exploitation, the hops culture stands out for presenting excellent nutritional characteristics, such as antioxidant properties, the presence of vitamin A and C, protein, pepsin and minerals. The hops plant belongs to the Solanaceae family and occurs naturally in the Andean regions. The objective of this study was to evaluate the effect of increasing doses of chicken manure in hops grown under organic production system. The experiment was installed in the experimental area FAFICH in Goiatuba-GO municipality in the period november 2014 to march 2015 . The experimental design was a randomized complete block design with four treatments and five repetitions. The treatments were: $0.0 ; 0.72 ; 2.17$ and $6.52 \mathrm{~kg}^{\text {plant }}{ }^{-1}$ of manure and each treatment was split into three equal doses. The plants were evaluated during the stages of growth, and the variables: plant height $(\mathrm{cm})$; stem diameter $(\mathrm{cm})$; length and width of sheet $3(\mathrm{~cm})$; early flowering (anthesis) and chlorophyll content. It was observed that the DAT 180 increased poultry manure doses provided significant growth in plants, obtaining the best results in dosage $\left(6.09 \mathrm{~kg} \mathrm{pl}^{-1}\right)$ where the plant height reached variable $32.35 \mathrm{~cm}$.
\end{abstract}

Key words: Nitrogen fertilization. Productive performance. Organic agriculture. Small fruits.

\footnotetext{
*Autor para correspondência

Recebido para publicação em 30/01/2016; aprovado em 12/03/2016

${ }^{1}$ Doutor em Fitotecnia (UFRRJ), Faculdade de Filosofia e Ciências Humanas, Goiatuba-GO; 64 - 81747835, uiraagro@gmail.com.

${ }^{2}$ Graduando em Engenharia Agronômica, UFG, gustavodepaulosouza@ gmail.com

${ }^{3}$ Graduanda em Engenharia Agronômica, FAFICH, isabellabsilva@outlook.com

${ }^{4}$ Engenheiro Agrônomo, FAFICH, mauricio_jlj@hotmail.com

${ }^{5}$ Graduanda em Engenharia Agronômica, FAFICH, valdineiaagm@ gmail.com
} 


\section{INTRODUÇÃO}

O cultivo de espécies frutíferas exóticas tem espaço importante na fruticultura brasileira, neste cenário o lulo se apresenta como alternativa de espécie a ser cultivada devido as suas características nutricionais. Gancel (2008) caracterizou química e fisicamente os frutos de lulo encontrando componentes nutricionais no fruto e na casca, tais como fibras dietéticas solúveis e insolúveis, proteínas, vitaminas A e C, polifenóis, antioxidantes e minerais como potássio e fósforo.

O lulo pertence à família Solanaceae e apresenta duas espécies principais Solanum quitoense Lam. e Solanum quitoense var. septentrionale, sendo a primeira desprovida de pelos e espinhos. Ambas espécies ocorrem naturalmente em regiões andinas onde as condições ecológicas são bem específicas, com altitudes entre 1200 a 2300 metros, solos úmidos e bem drenados, e precipitação mínima de $2032 \mathrm{~mm}$ anuais (HEISER; ANDERSON, 1999).

Segundo Nuro (2012) o lulo (Solanum quitoense var. septentrionale) é uma planta herbácea que pode atingir $2,5 \mathrm{~m}$ de altura, caule de coloração marrom-esverdeado e com pilosidade intensa. As plantas podem apresentar desenvolvimento de 4 a 7 ramos secundários até o período de floração. As folhas são denteadas e distinguem-se em 3 estágios de maturação distintos: as basais são grandes, coriáceas e de coloração verde-escuro; as medianas são menores e verde-claras; as apicais são ainda menores e de coloração arroxeada. E a frutificação se inicia do oitavo ao décimo mês e a colheita pode se estender por até dois anos. Seu fruto é do tipo baga de coloração alaranjada, motivo pelo qual também é conhecido por 'naranjilla' em outras partes do mundo.

No sistema orgânico de produção de alimentos, priorizase a adubação orgânica, que apresenta como principais características a melhoria das propriedades físicas, químicas e biológicas do solo (PIVA et al., 2013). Neste sentido, a adubação orgânica é o sustentáculo de vários sistemas de produção para muitas espécies vegetais. Malavolta (1980) sugeri que os materiais orgânicos, além de melhorarem as condições físicas e biológicas do meio, desempenham importante papel na nutrição das plantas por apresentarem na sua constituição nutrientes como N, P, S. Segundo Huett; Dettmann (1988), o nitrogênio (N), comparado aos outros nutrientes, tem maior efeito sobre as taxas de crescimento e absorção de elementos, sendo, portanto, mais importante em termos de controle da nutrição ótima das culturas.

A grande maioria dos trabalhos encontrados na literatura diz respeito ao uso de estercos, resíduos líquidos e restos vegetais, reportando seu efeito como melhoradores do solo e fornecedores de nutrientes (KIEHL, 1985). O esterco de ave poedeira é considerado fonte importante de nutrientes para os vegetais devido sobretudo ao elevado teor de $\mathrm{N}$ (BOATENG et al., 2006). Segundo Mueller et al. (2013) a produtividade comercial máxima estimada do tomateiro cv. 'Alambra', na safra 2007/08, quando adubado somente com cama de aviário foi $86,9 \mathrm{t} \mathrm{ha}^{-1}$ de frutos de tomate na dose de $16,2 \mathrm{t} \mathrm{ha}^{-1}$.

Diante deste contexto e pela falta de informações sobre o comportamento da espécie Solanum quitoense var. septentrionale nas condições edafoclimáticas do cerrado brasileiro. O objetivo deste trabalho foi avaliar o desempenho das plantas de lulo do transplantio ao florescimento quando adubadas com diferentes quantidades de esterco de galinha.

\section{MATERIAL E MÉTODOS}

O trabalho foi realizado no período de novembro de 2014 a março de 2015, na área experimental da Faculdade de Filosofia e Ciências Humanas (FAFICH) no município de Goiatuba, Estado de Goiás. O local apresenta as seguintes coordenadas geográficas; longitude oeste 50¹9’30”; latitude sul $27^{\circ} 48^{\prime} 17^{\prime}$ 'S e altitude média de $815 \mathrm{~m}$.

A análise de solo realizada antes do cultivo apresentou os seguintes valores: $\mathrm{pH}$ (em água) $=4,9 ; \mathrm{P}=3,7 \mathrm{mg} \mathrm{dm}^{-3}$; $\mathrm{K}=0,13 \mathrm{cmol} \mathrm{dm}^{-3} ; \mathrm{Ca}=1,1 \mathrm{cmol} \mathrm{dm}^{-3} ; \mathrm{Mg}=0,4 \mathrm{cmol} \mathrm{dm}^{-3}$; $\mathrm{Al}=0,1 \mathrm{cmol} \mathrm{dm}^{-3} ; \mathrm{T}=1,7 \mathrm{cmol} \mathrm{dm}^{-3} ; \mathrm{V}=30 \% ; \mathrm{SB}=1,6 \mathrm{cmol}$ $\mathrm{dm}^{-3} ; \mathrm{CTC}=6,1 \mathrm{cmol} \mathrm{dm}^{-3}$.

Foram usadas plantas de lulo da variedade septentrionale, cuja as mudas foram produzidas a partir de sementes, em telado. As sementes foram adquiridas da empresa Sambalinas Sementes ${ }^{\circledR}$ e semeadas em quatro bandejas de isopor de 128 células contendo substrato comercial Bioflora ${ }^{\circledR}$ com os constituintes, casca de eucalipto, vermiculita, carvão vegetal, rocha calcária, superfosfato simples, nitrato de amônio, esterco bovino, farelos e tortas de origem vegetal. Quando as plantas apresentaram três folhas expandidas as mudas foram transplantadas para sacos plásticos com substrato orgânico, composto por esterco bovino, terra de barranco e areia (3:2:1) e foram transplantadas aos 45 dias após a semeadura, quando estavam com uma altura variando entre 10 a $15 \mathrm{~cm}$.

$\mathrm{Na}$ área experimental, as mudas foram plantadas usando espaçamento de 2,0 × 2,0 m, em covas de $0,30 \times 0,30 \times 0,30$ $\mathrm{m}$, correspondentes à largura, comprimento e profundidade. A irrigação foi realizada manualmente e o controle de plantas daninhas foi realizado sempre que necessário por meio de capinas manuais.

O delineamento experimental foi em blocos casualizados, com quatro tratamentos e cinco repetições, cujos tratamentos consistiram na aplicação de diferentes doses de esterco de aves curtido: 0,0;0,72;2,17 e 6,52 kg planta $^{-1}$. Sendo que cada tratamento foi fracionado em três doses iguais, a primeira aplicação logo após a abertura das covas; e as demais com intervalos de trinta dias.

A parcela foi composta por 15 plantas, totalizando 375 plantas. Sendo a área útil da parcela constituída pelas três plantas centrais.

As variáveis avaliadas foram realizadas com intervalos de 30 dias (120, 150 e 180 dias), sendo:

- Altura da planta $(\mathrm{cm})$ : medida com uma trena graduada em metros;

- Diâmetro do caule $(\mathrm{cm})$ : medido com auxílio de paquímetro nos primeiros $10 \mathrm{~cm}$ do caule;

- Número de folhas: contagem visual das folhas;

- Comprimento da terceira folha $(\mathrm{cm})$ : terceira folha medida com trena graduada em metros;

- Largura da terceira folha $(\mathrm{cm})$ : terceira folha medida com uma trena graduada em metros;

- Índice SPAD (Soil Plant Analysis Development): determinado por meio do uso de um clorofilômetro digital (SPAD 502DL) e incidência de insetos, ácaros e doenças por meio de observações visuais.

Os dados foram submetidos aos testes preliminares para verificação da normalidade e homogeneidade de variância dos mesmos pelo teste de Bartlett. Posteriormente, foram submetidos à análise de variância. Para auxiliar na escolha do modelo, foi considerada a significância dos coeficientes da 
equação de regressão ajustada, testados pelo teste ' $\mathrm{t}$ ' de Student, bem como os valores do coeficiente de determinação $\left(\mathrm{R}^{2}\right)$ associado a cada modelo de regressão. As análises estatísticas foram realizadas com o auxílio do programa estatístico SISVAR (FERREIRA, 2008).

\section{RESULTADOS E DISCUSSÃO}

Os resultados da análise de variância apresentaram efeito significativo entre os tratamentos para a maioria das variáveis analisadas nas três épocas de avaliação, com exceção para altura de plantas, diâmetro do caule, número de folhas aos 120 dias após o transplantio (DAT) e número de folhas aos 150 DAT (Tabela 1).

Tabela 1. Valores médios e equação de regressão das variáveis altura de plantas, diâmetro do caule, número de folhas, comprimento da terceira folha, largura da terceira folha e índice SPAD em razão de diferentes doses de esterco de aves.

\begin{tabular}{|c|c|c|c|c|c|c|}
\hline \multirow{2}{*}{ DAT } & \multicolumn{4}{|c|}{ Doses de esterco de aves $\left(\mathrm{kg} \mathrm{pl}^{-1}\right)$} & \multirow{2}{*}{ Equação de regressão } & \multirow{2}{*}{$\mathrm{R}^{2}$} \\
\hline & 0 & 0,72 & 2,17 & 6,52 & & \\
\hline & \multicolumn{4}{|c|}{ Altura de plantas $(\mathrm{cm})$} & & \\
\hline 120 & 10,07 & 11,00 & 11,57 & 10,13 & $\hat{y}=7,716+2,990 x-0,583 x^{2 n s}$ & 0,92 \\
\hline 150 & 15,77 & 17,03 & 20,80 & 17,50 & $\hat{\mathrm{y}}=9,325+7,371 \mathrm{x}-1,308 \mathrm{x}^{2} *$ & 0,78 \\
\hline \multirow[t]{2}{*}{180} & 22,73 & 27,27 & 36,20 & 37,73 & $\hat{\mathrm{y}}=13,750+9,143 \mathrm{x}-0,750 \mathrm{x}^{2} *$ & 0,95 \\
\hline & \multicolumn{4}{|c|}{ Diâmetro do caule $(\mathrm{cm})$} & & \\
\hline 120 & 0,51 & 0,56 & 0,64 & 0,52 & $\hat{y}=0,516+0,270 x-0,050 x^{2 n s}$ & 0,98 \\
\hline 150 & 0,70 & 0,95 & 1,00 & 1,03 & $\hat{\mathrm{y}}=0,450+0,280 \mathrm{x}-0,033 \mathrm{x}^{2} *$ & 0,99 \\
\hline \multirow[t]{2}{*}{180} & 0,96 & 1,59 & 1,62 & 1,80 & $\hat{y}=0,295+0,813 x-0,111 x^{2}$ & 0,93 \\
\hline & \multicolumn{4}{|c|}{ Número de folhas } & & \\
\hline 120 & 4,60 & 5,07 & 5,13 & 4,93 & $\hat{y}=3,833+0,940 x-0,166 x^{2 n s}$ & 0,99 \\
\hline 150 & 5,00 & 5,00 & 5,67 & 5,40 & $\hat{\mathrm{y}}=4,466+0,520 \mathrm{x}-0,066 \mathrm{x}^{2 \mathrm{~ns}}$ & 0,60 \\
\hline \multirow[t]{2}{*}{180} & 6,60 & 8,53 & 11,07 & 11,87 & $\hat{y}=3,516+3,250 x-0,283 x^{2} *$ & 0,98 \\
\hline & \multicolumn{4}{|c|}{ Comprimento da $3^{\mathrm{a}}$ folha } & & \\
\hline 120 & 10,33 & 11,53 & 14,11 & 11,57 & $\hat{y}=5,683+5,496 x-0,983 x^{2} *$ & 0,71 \\
\hline 150 & 14,37 & 18,17 & 19,63 & 19,00 & $\hat{y}=8,958+6,235 \mathrm{x}-0,925 \mathrm{x}^{2} *$ & 0,98 \\
\hline \multirow[t]{2}{*}{180} & 20,60 & 29,27 & 29,87 & 32,60 & $\hat{\mathrm{y}}=11,516+11,076 \mathrm{x}-1,48 \mathrm{x}^{2} *$ & 0,93 \\
\hline & \multicolumn{4}{|c|}{ Largura da $3^{\mathrm{a}}$ follha } & & \\
\hline 120 & 9,27 & 10,48 & 12,17 & 10,83 & $\hat{y}=6,383+3,650 x-0,616 x^{2} *$ & 0,82 \\
\hline 150 & 13,95 & 17,67 & 19,50 & 18,27 & $\hat{y}=8,020+6,804 x-1,050 x^{2} *$ & 0,96 \\
\hline \multirow[t]{2}{*}{180} & 18,73 & 27,67 & 28,67 & 31,13 & $\hat{\mathrm{y}}=8,916+11,903 \mathrm{x}-1,616 \mathrm{x}^{2} *$ & 0,94 \\
\hline & & Índic & SPAD & & & \\
\hline 120 & 34,77 & 40,59 & 42,05 & 43,19 & $\hat{y}=28,350+7,870 x-1,050 x^{2} *$ & 0,98 \\
\hline 150 & 35,81 & 43,81 & 44,25 & 49,22 & $\hat{y}=24,400+8,000 x-0,800 x^{2} *$ & 0,91 \\
\hline 180 & 38,38 & 47,11 & 47,49 & 52,96 & $\hat{\mathrm{y}}=31,400+8,440 \mathrm{x}-0,800 \mathrm{x}^{2} *$ & 0,92 \\
\hline
\end{tabular}

Na Figura 1 é possível observar que a dosagem máxima de 6,09 $\mathrm{kg} \mathrm{planta}^{-1}$ proporcionou maior crescimento da planta, com valor médio de altura de plantas igual a $32,35 \mathrm{~cm}$ aos 180 dias após o transplantio.

Figura 1. Altura de plantas lulo (Solanum quitoense var. septentrionale) aos 180 dias após o transplantio.

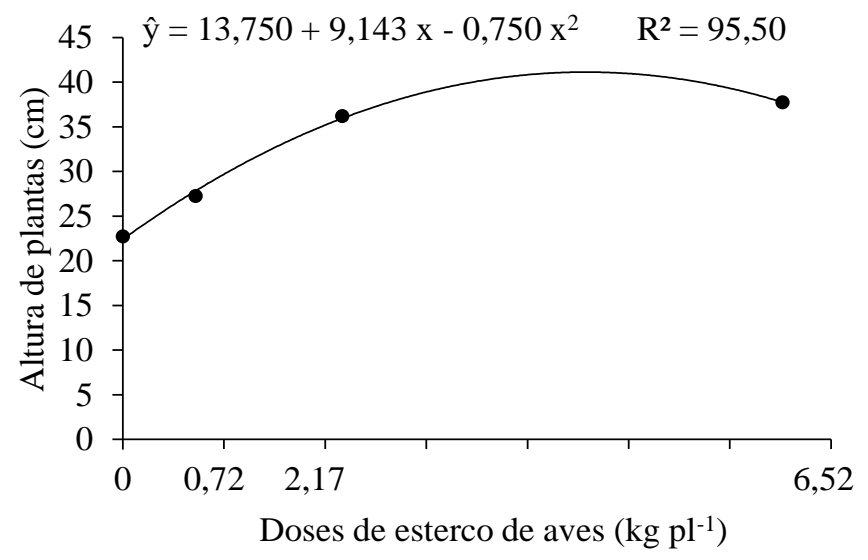

Segundo Shen et al. (1994), trabalhando com a ausência de adubação nitrogenada (testemunha), foram observados os menores valores de altura de plantas de cevada, com média dos dados de crescimento acumulado de $82,93 \mathrm{~cm}$, uma diferença de $12 \mathrm{~cm}$ em relação à maior média obtida, 95,71 $\mathrm{cm}$, correspondente à maior dose aplicada.

Mais recentemente, Medeiros et al. (2015) avaliando o crescimento inicial da berinjeleira cv. Embú sob adubação nitrogenada e fosfatada e irrigada com água de reuso, não observaram efeito significativo nas variáveis altura de planta, diâmetro caulinar e número de folhas.

O diâmetro do caule foi maior para a dose de $3,66 \mathrm{~kg} \mathrm{pl}^{-}$ 1 de esterco de aves, sendo o valor estimado de $1,78 \mathrm{~cm}$ (Figura 2).

Figura 2. Diâmetro de plantas lulo (Solanum quitoense var. septentrionale) aos 180 dias após o transplantio.

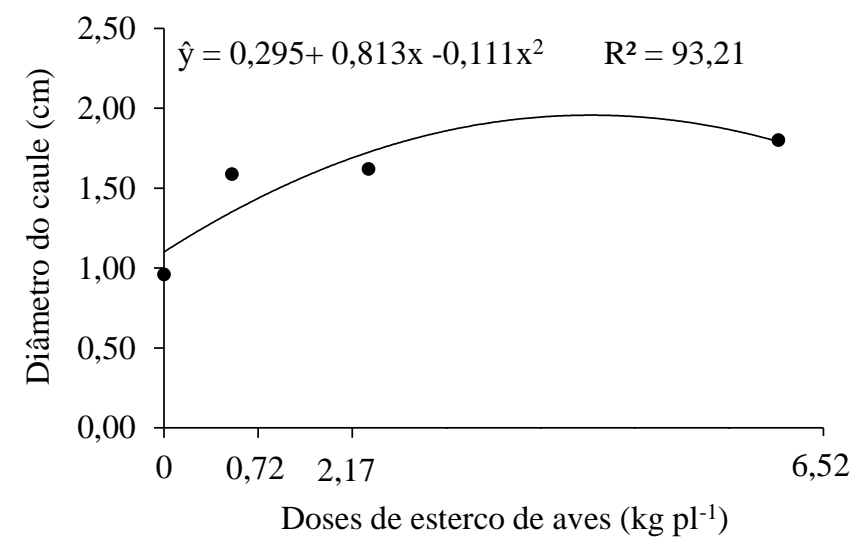

Guertal; Kemble, (1998), não encontraram valores significativos para diâmetro do caule, testando diferentes fontes de nitrogênio na cultura do tomateiro. Já para Biscaro et al. (2008) ao avaliar o efeito da adubação nitrogenada em cobertura na cultura do girassol irrigado, observaram que a variável diâmetro do caule apresentou comportamento quadrático, sendo que o aumento do diâmetro do caule foi até a dose máxima estimada de $47,8 \mathrm{~kg} \mathrm{ha}^{-1} \mathrm{de} \mathrm{N}$, chegando a um crescimento médio do caule de $18,4 \mathrm{~mm}$.

Para variável número de folhas a dose $5,74 \mathrm{~kg} \mathrm{pl}^{-1}$ proporcionou uma emissão máxima de 10,77 folhas por planta aos 180 DAT (Figura 3).

Figura 3. Número de folhas de plantas lulo (Solanum quitoense var. septentrionale) aos 180 dias após o transplantio.

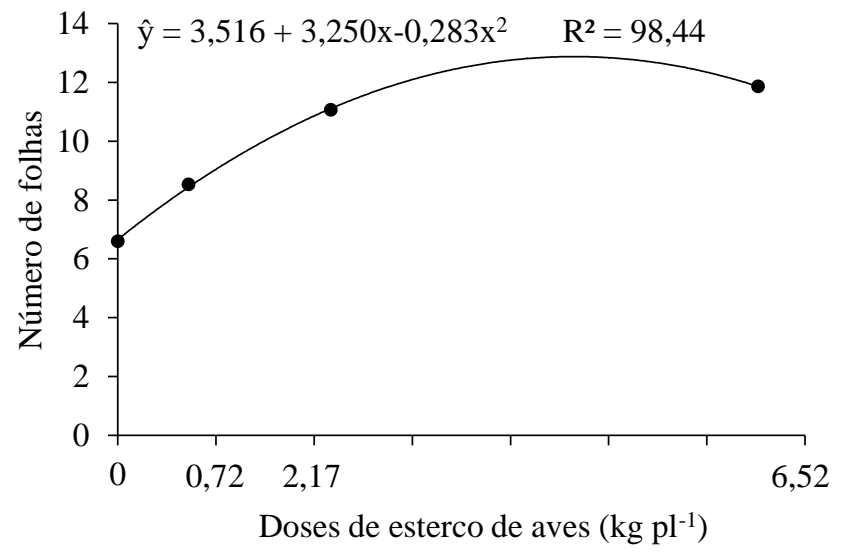


O comprimento e a largura da terceira folha apresentaram os maiores valores $50,90 \mathrm{~cm}$ e $38,91 \mathrm{~cm}$ nas dosagens de $3,73 \mathrm{~kg} \mathrm{pl}^{-1}$ e $3,68 \mathrm{~kg} \mathrm{pl}^{-1}$, respectivamente (Figuras 4 e 5).

Figura 4. Comprimento da $3^{\text {a }}$ folha de plantas lulo (Solanum quitoense var. septentrionale) aos 180 dias após o transplantio.

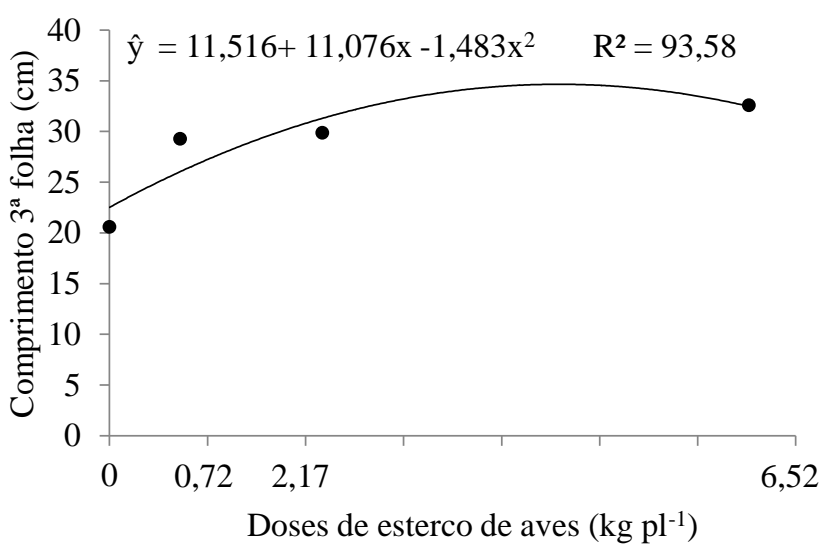

Figura 5. Largura da $3^{\text {a }}$ folha de plantas lulo (Solanum quitoense var. septentrionale) aos 180 das após o transplantio.

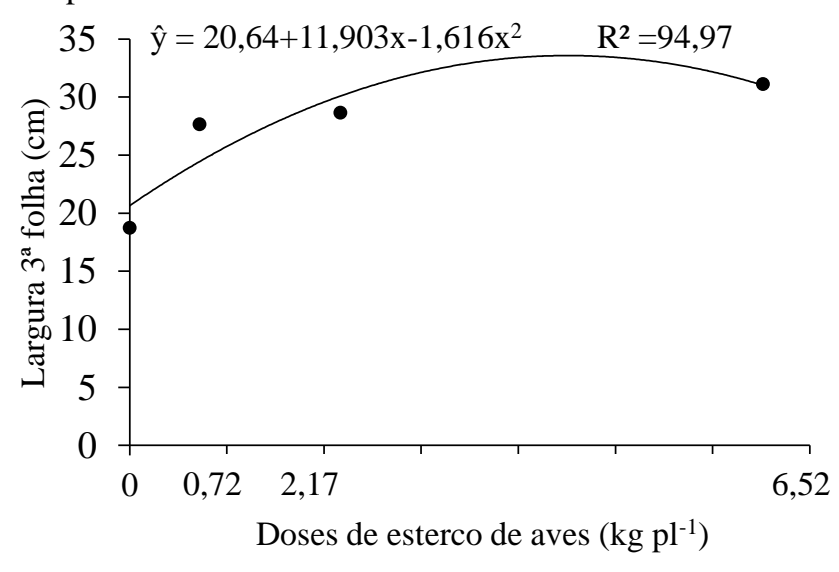

Os valores das leituras feitas no medidor SPAD aumentaram curvilinearmente em função das doses de $\mathrm{N}$, ajustando-se ao modelo quadrático. A partir da curva apresentada a maior dosagem do esterco de aves foi de 5,27 $\mathrm{kg} \mathrm{pl}^{-1}$ para um valor SPAD de 48,10 (Figura 6).

Figura 6. Índice SPAD de plantas lulo (Solanum quitoense var. septentrionale) aos 180 dias após o transplantio.

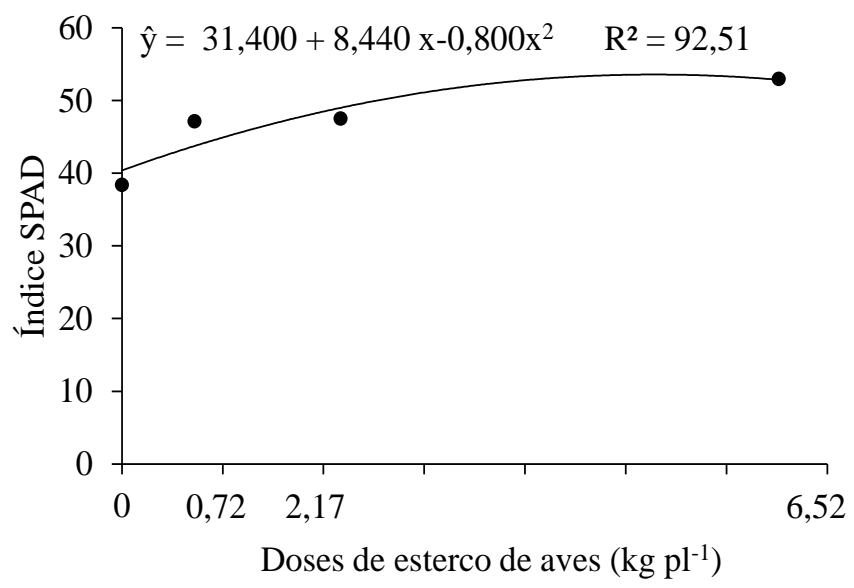

Ferreira et al. (2006) trabalhando com tomateiro, também constataram aumento nos valores SPAD de folhas quando as taxas de fertilização nitrogenada do solo foram aumentadas. Segundo Porto et al. (2014) plantas de tomateiro híbrido Silvety aumentaram linearmente os valores médios de SPAD de acordo com o aumento das doses de nitrogênio. Sendo que o maior valor de leitura SPAD foi para plantas tratadas com nitrato de cálcio.

$\mathrm{O} N$ é um nutriente que participa da síntese e da estrutura das moléculas de clorofila (FONTES; ARAÚJO, 2007). A clorofila é o pigmento envolvido na fotossíntese e, correlações positivas entre teor relativo de clorofila (Índice SPAD) e os teores de nitrogênio da planta têm sido observadas por diversos autores em outras Solanáceas (ZUFFO et al., 2012).

No entanto, o $\mathrm{N}$ em altas quantidades predispõe às plantas a ação de certas pragas e patógenos provavelmente devidos à maior suculência (SILVA, 1994). Neste sentido, foi observado apenas a ocorrência de mosca branca (Bemisia argentifolii) e cochonilha (Icerya purchasi) sem prejuízos a cultura do lulo.

\section{CONCLUSÕES}

O esterco de aves curtido propiciou o melhor crescimento da cultura de lulo a partir da dose de $6,09 \mathrm{~kg} \mathrm{pl}^{-1}$. Doses superiores a $2,17 \mathrm{~kg}$ planta $^{-1}$ estimularam o florescimento das plantas de lulo a partir dos 120 dias após o transplantio.

\section{REFERÊNCIAS BIBLIOGRÁFICAS}

BISCARO G. A.; MACHADO, J. R.; TOSTA, M. S.; MENDONÇA, V.; SORATTO, R. P.; CARVALHO, L. A. Adubação nitrogenada em cobertura no girassol irrigado nas condições de Cassilândia-MS. Ciência e Agrotecnologia, v.32, n.5, p.1366-1373, 2008

BOATENG, S.A.; ZICKERMANN, J.; KORNAHRENS, M. Poultry manure effect on growth and yield of maize. West Africa Journal of Applied Ecology, v.9, p.1-11, 2006.

FERREIRA, M. M. M.; FERREIRA, G. B.; FONTES, P. C. R.; DANTAS, J. P. Índice Spad e teor de clorofila no limbo foliar do tomateiro em função de doses de nitrogênio e da adubação orgânica, em duas épocas de cultivo. Revista Ceres, Viçosa, v. 53, n. 305, p. 83-92, 2006.

FERREIRA, D.F. SISVAR: um programa para análises e ensino de estatística. Revista Symposium, v.6, p.36-41, 2008.

FONTES, P. C. R.; ARAÚJO, C. Adubação nitrogenada de hortaliças: princípios e práticas com o tomateiro. Viçosa: FV. 148p. 2007.

GANCEL, A.L.; ALTER, P.; MAYER, C.D.; RUALES, J.; VAILLANT, F. Identifying carotenoids and phenolic compounds in naranjilla (Solanum quitoense Lam. var. Puyo Hybrid), an Andean fruit. Journal of agricultural and food chemistry, v. 56, p. 11890-11899. 2008. 
GUERTAL, E. A.; KEMBLE, J. M. Response of field-grown tomatoes to nitrogen sources. Hort. Techn., 8(3):386-91. 1998.

HEISER, C. B.; ANDERSON, G. New solanums. In: Janick J. (ed). Perspectives on new crops and new uses. ASHS Prees, Alexandria V., p. 379-384. 1999.

HUETT, D. O., DETTMANN, E. B. Effect of nitrogenon growth, fruit quality and nutriente uptake of tomatoes grown in sand culture. Australian Journal of Experimental Agriculture, v.28, n.3, p.391-399, 1988.

KIEHL, E.J. Fertilizantes orgânicos. São Paulo: Agronômica Ceres, 1985. $492 \mathrm{p}$.

MALAVOLTA, E. Avaliação do estado nutricional, In: Elementos de nutrição mineral de plantas, São Paulo: Ceres, 1980. p.219-251.

MEDEIROS, A. de S.; NOBRE, R. G.; FERREIRA, E. da S.; ARAÚJO, W. L.; QUEIROZ, M. M. F. Crescimento inicial da berinjeleira sob adubação nitrogenada e fosfatada e irrigada com água de reuso. Revista Verde, v. 10, n.3, p 3440, jul-set, 2015.

MUELLER S; WAMSER AF; SUZUKI A; BECKER WF. Produtividade de tomate sob adubação orgânica e complementação com adubos minerais. Horticultura Brasileira. v. 31, n. 1, p. 86-92. 2013.

NURO, A. Absorção de nutrientes pela cultura de lulo (Solanum quitoense Lam. variedade septentrionale). 2012. 42 f. Dissertação (Pós-Graduação em Fitotecnia) - Universidade Federal de Viçosa, Viçosa, 2012.

SILVA, J. B. C.; GIORDANO, L. de B.; BOITEUX, L. S.; LOPES, C. A.; FRANCA, F. H.; SANTOS, J. R. M.; FURUMOTO, O.; FONTES, R. R.; MAROUELLI, W. A.; NASCIMENTO, W. M.; SILVA, W. L. C.; PEREIRA, W. Cultivo do tomate (Lycopersicon esculentum Mill) para a industrialização. Brasília: EMBRAPA-CNPH, 1994. 36p. (EMBRPA-CNPH. Instrução Técnica, 12).

PIVA, R.; BOTELHO, R. V.; ORTOLAN, C.; MÜLLER, M. M. L.; KAWAKAMI, J. Adubação em vinhedo orgânico da cv. Isabel utilizando cinzas vegetais e esterco bovino. Revista Brasileira de Fruticultura, v.35, n. 2, p. 608-615, jun. 2013.

PORTO, J. S.; AMORIM, Y. F.; REBOUÇAS, T. N. H.; LEMOS, O. L.; LUZ, J. M. Q.; COSTA, R. Q. Índice SPAD e crescimento do tomateiro em função de diferentes fontes e doses de nitrogênio. Scientia Plena, v. 10, n. 11, p. 2-8. 2014.

SHEN, Z.; SHEN, Q.; LIANG, Y.; LIU, Y 1994. Effect of nitrogenon the growth and photosynthetic activity of saltstressed barley. Journal Plant Nutrition. v. 17: p.787-799, 1994.

ZUFFO, A. M.; ANDRADE, F. R.; SCHOSSLER, T. R.; MILHOMEM, D. M.; PIAUILINO, A.C. Eficiência na determinação indireta do nitrogênio foliar a partir do índice SPAD. Enciclopédia Biosfera, 8(15); 805-820. 2012. 